\title{
Virtual Reality in Higher Education
}

\author{
Christian P Fabris ${ }^{\mathrm{a}}$, Joseph A. Rathner ${ }^{\mathrm{a}}$, Angelina Y. Fong ${ }^{\mathrm{a}}$, and Charles P. Sevigny, \\ Corresponding author: Charles P. Sevigny, sevignyc@unimelb.edu.au \\ ${ }^{a}$ Department of Physiology, University of Melbourne, Victoria, 3010, Australia \\ ${ }^{\mathrm{b}}$ School of Biomedical Sciences, University of Melbourne, Victoria, 3010, Australia
}

Keywords: virtual reality; VR; scalability; education technology; active learning; simulation

\begin{abstract}
Virtual reality (VR) is an interactive experience which immerses the user in a digital environment through a sense of presence. In the context of providing an active learning experience, virtual reality has the potential to improve learning outcomes for biomedical science students as it allows the visualisation of and interaction with digital representations of dynamic objects and complex concepts. Studies in bioscience and medical education have shown mixed results pertaining to the benefits of VR as a learning tool. This review aims to consolidate how VR succeeded or failed in improving learning outcomes, and assesses the issue of VR scalability for the ever-growing cohorts in tertiary bioscience courses.
\end{abstract}

\section{Raison d'être for this review}

Reviews relating to virtual reality (VR) and education have previously been conducted (Freina \& Ott, 2015; Merchant, Goetz, Cifuentes, Keeney-Kennicutt, \& Davis, 2014). However, these papers have not discussed in detail the reasons for the successes and failures of virtual reality as an educational tool, nor the deployment of the technology on a large scale, points into which this paper hopes to delve. Freina and Ott (Freina \& Ott, 2015) broadly reported on the current uses of virtual reality in education research, and Merchant and colleagues (Merchant et al., 2014) briefly note the previous challenges facing mass deployment.

\section{What is Virtual Reality?}

\section{Virtual: The New Frontier}

"Virtual" - adjective; almost or nearly as described, but not completely or according to strict definition. With this definition, we can begin to understand the concept of "Virtual Reality"; in essence, an attempt to replicate reality as we know it. VR is an interactive experience wherein one can become immersed within a computer-generated environment. In academic literature, VR can encompass programmes that are simply viewed on a flat screen, such as a desktop monitor or tablet device, as well as those that require the use of "goggles" and other head-mounted displays (HMDs).

In creating programmes and devices for VR, developers work to convey feelings of 'immersion' and 'presence' to the user such that the environment experienced is perceived as "real" by the user (Freina \& Ott, 2015). Presence is the psychological impression upon the user that the environment they are experiencing is real, while immersion is the attempt by the technology to instil that sense of presence (Mestre, 2006). A technology which presents stimulatory information that increasingly resembles what the user considers "real" is said to be more immersive and thus causes greater presence. Temporal elements often accompany the spatial in VR programmes, which allows for viewed environments and objects to change over time before the user, and the use of certain controllers allows for haptic feedback to the hands, 
increasing immersion. In an educational context, the sense of presence might reflect the authenticity of an experience. In a simulated anatomy dissection, this may be measured as the degree that the student believed they were viewing a prosected specimen rather than a simulation thereof.

Due to the immense associated costs, VR technology has, until recently, been restricted to larger industrial and laboratory settings (Castelvecchi, 2016), particularly in psychology research, and has hence limited the ability to deploy the technology as a generic teaching tool. However, recent advances by various HMD VR companies has seen the proliferation of affordable, lightweight HMD products to the wider community (Riva \& Wiederhold, 2015) and has generated renewed interest in its range of applications, including education.

\section{VR - More than Just a Game}

Though widely considered by the public to be an entertainment technology, VR has demonstrated utility in a variety of applications, ranging from preparing surgeons and patients for operations and aiding in mental health, to education in bioscience, chemistry, physics and engineering (Borrel \& Fourches, 2017; Botella, Serrano, Banos, \& Garcia-Palacios, 2015; Cha et al., 2016; Chirico et al., 2016; Cho et al., 2002; Goddard et al., 2018; Hoffman et al., 2008; O'Connor et al., 2018; Parkhomenko et al., 2018; Pulijala, Ma, Pears, Peebles, \& Ayoub, 2018a, 2018b; Teranishi \& Yamagishi, 2018). Multiple studies have demonstrated the effectiveness of VR in healthcare scenarios, including: (i) improved informed consent by allowing patients to visualise recommended procedures (Parkhomenko et al., 2018), (ii) pain management (Chirico et al., 2016; Hoffman et al., 2008), (iii) Post Traumatic Stress Disorder treatment (Botella et al., 2015), and (iv) preparing surgeons for surgery (Cha et al., 2016; Parkhomenko et al., 2018; Pulijala et al., 2018a, 2018b). Additionally, Cho and colleagues (Cho et al., 2002) observed that juvenile delinquents saw greater improvements in their attention spans when they underwent cognitive training courses in HMD VR compared to using a standard flat-screen computer.

In this review, we will discuss the potential for VR in biomedical science courses. The concepts taught in such courses often rely heavily on visual-spatial understanding of anatomical structures and their orientation and many of the physiological and biochemical processes are dynamic. The totality of these structures and their functions are poorly represented by two dimensional illustrations, and yet students are frequently required to visualise and understand these three dimensional concepts and dynamic mechanisms from static sources, such as textbooks and lecture slides (Stepan et al., 2017). Depending on the design of the programme used, VR can allow dynamic processes to be viewed from various angles and depths, as can be seen in applications such as "Share Care VR" (available on the Steam VR Store for free as of August 2019) (Maresky et al., 2019). Indeed, VR can improve visual-spatial understanding, such as with the learning of the correct positioning of installed computer parts (Teranishi \& Yamagishi, 2018) and of cardiac anatomy (Maresky et al., 2019).

\section{VR as an Active Learning and Engaging Tool}

Traditionally, education placed emphasis on the teacher rather than the student, such that the teacher was considered most important in determining what is learnt (Michael, 2006). However, this model has been consistently challenged and usurped by student-orientated learning and teaching styles in a variety of fields, where students actively engage with the learning material and direct their own learning under an instructor's guidance. Students are encouraged to work with their peers and are pushed to analyse the concepts taught in order to actively understand 
the information rather than passively accepting it as truth (Collins \& O'Brien, 2011; Michael, 2006). This is active learning, a teaching style which has clearly had a significant impact on student learning (Betihavas, Bridgman, Kornhaber, \& Cross, 2016; Freeman et al., 2014; Koh, Khoo, Wong, \& Koh, 2008; Michael, 2006; Sisk, 2011).

VR has the potential to act as an active learning tool and enhance the educational experience in bioscience, as it encourages active participation and self-directed learning of a student through high-levels of interactivity with the software. This is important as medical and bioscience education often requires students to be able to physically interact with objects, such as organs, to gain a better understanding of their form through self-directed inquiry and exploration (Maresky et al., 2019). Many programmes designed for HMD VR allow students to interact with the virtual environment in a variety of ways, one being through the use of handheld controllers which deliver haptic feedback or technology such as 'Leap Motion' which tracks hand and digit movements. A number of papers have studied interactive VR programmes as educational tools, exhibiting a myriad of associated benefits, such as improvements in visual understanding, long term retention and revision of concepts, as well as engagement with and enjoyment of the learning activity (Maresky et al., 2019; Marsh, Giffin, \& Lowrie, 2008; Stepan et al., 2017; Teranishi \& Yamagishi, 2018), as described further in Section 4. However, when students are constrained by a lack of appropriate, intuitive hand controls, improvements in learning could be limited (Makransky, Terkildsen, \& Mayer, 2019). Moreover, simply having a VR programme in a course does not generate active learning as the tool can be used in a very passive manner as well. For example, Stepan and colleagues used a "flyover" video in the first half of their VR intervention phase which subjects watched through HMD VR (Stepan et al., 2017). Additionally, it should be noted that VR technology, though no longer nascent, is still young and therefore is not perfect. Some limitations of varying severity range from motion sickness to an inability for HMDs to comfortable fit around large religious headwear. Though VR cannot, as yet, fully replicate the tactile sensation experienced from physically interacting with an object (thus limiting the sense of presence conveyed), it does allow for the digital simulation to be manipulated and explored in a similar manner to the real thing, highlighting the interactive capability of the technology and its potential use as an active learning tool.

Enjoyment and engagement with a learning tool has been identified as conducive to a better student learning experience as these experiences can promote self-confidence and make the task valued by and relevant to the user, driving engagement and motivation to learn (Jang, 2008; Kahu, Nelson, \& Picton, 2017). A number of papers have reported high levels of engagement and enjoyment in the use of VR programmes (Brewer, Wilson, Eagleson, \& de Ribaupierre, 2012; Harrington et al., 2018; Stepan et al., 2017), which can be attributed to the immersion capabilities of the technology (Chessa, Maiello, Borsari, \& Bex, 2016). Chessa and colleagues demonstrated that subjects experienced changes in their heart rate when placed atop a virtual building and "dropped" to the street below, and also instinctively moved around approaching virtual objects despite their absence in the real world (Chessa et al., 2016). This exemplifies the sense of presence that users can experience in VR, highlighting the potential for VR programmes to be used as engaging learning tools.

\section{Education Transformer or Shiny Distraction?}

Recent improvements in affordability and accessibility (Castelvecchi, 2016) has seen a breadth of studies take place that have sought to determine the potential viability of VR as an educational tool. 


\section{A Breadth of Applications}

A variety of tools that can be implemented into educational courses have been developed using VR technology. Several of these programmes focus on the visualisation of atoms and molecules whilst using a HMD VR system (Borrel \& Fourches, 2017; Goddard et al., 2018; O'Connor et al., 2018), and others facilitate the study of electron and light microscopy (Goddard et al., 2018), though the benefits of these tools after course implementation have not been described. Many other educational VR programmes have been developed and their benefits on learning outcomes studied in the fields of biomedical science education (Brewer et al., 2012; Codd \& Choudhury, 2011; Garg, Norman, \& Sperotable, 2001; Garg, Norman, Eva, Spero, \& Sharan, 2002; Garg, Norman, Spero, \& Maheshwari, 1999; Maresky et al., 2019; Marsh et al., 2008; Stepan et al., 2017), medical preparation and training (Cha et al., 2016; Harrington et al., 2018; Parkhomenko et al., 2018; Pulijala et al., 2018a, 2018b), as well as in computer engineering (Teranishi \& Yamagishi, 2018). Furthermore, Mahaffey et al have previously designed an undergraduate physiology course with a focus on the implementation of VR physiology laboratories alongside a variety of e-learning resources (such as electronic textbooks, online home-work and animations), face-to-face classes, and student led case studies (Mahaffey, 2018). The new course resulted in a 99\% pass rate for students (although previous pass rates were not detailed in the paper) and exhibits one example of how VR has already been implemented into education.

\section{Effects of Virtual Reality on Learning}

Virtual reality has demonstrated a variety of effects on student results and learning outcomes. However, this may be largely dependent on the design and delivery of VR programmes.

\section{Changes in student results}

Seven of the papers presented in this review measured the effect of VR on student learning through pre-/post-knowledge tests. Though not necessarily a definitive measurement of learning, improvements on these tests are attention-grabbing and their use is widespread in the literature. After a variety of VR interventions, two papers saw statistically significant improvements on knowledge tests (Maresky et al., 2019; Marsh et al., 2008), four found no significant differences (Brewer et al., 2012; Pulijala et al., 2018a; Stepan et al., 2017; Teranishi \& Yamagishi, 2018) and one implies that VR can have a negative effect on learning, possibly due to limitations in its interactivity (Makransky et al., 2019). The notable outcomes of these studies are detailed on Table 1 below.

However, only one paper stratified the learning materials in their study design such that the study group was exposed only to a VR programme and the control group had access only to conventional materials (in this case, a PowerPoint presentation) (Pulijala et al., 2018a), whilst a second compared HMD VR to desktop VR without any implementation of other, older teaching methodologies (Makransky et al., 2019) and a third did not present a control group (Teranishi \& Yamagishi, 2018). This suggests that the benefits of VR, when seen, could be due in part to the implementation of diverse learning resources together, as opposed to the VR alone, discussed further in Section 4.2c.

\section{Learning outcomes}

VR has demonstrated the potential to add to the student learning experience beyond improvements in knowledge-based tests. For instance, Marsh, Giffin and Lowrie showed evidence that VR can assist with revision of topics previously studied, as well as improving long term retention of knowledge gained from a course (Marsh et al., 2008). 
VR also has benefits for learning manual skills and improving the spatial understanding of complex objects. Parkhomenko and colleagues (Parkhomenko et al., 2018) reported that surgeons had significantly higher self-perceived ratings of their understanding of upcoming kidney surgeries after viewing CT scans and VR recreations of a patient's kidney and kidney stones compared to viewing the CT scan alone. This is because the surgeons were able to better visualise the anatomy, anatomical variations and specific location of the kidney stones, meaning they could attempt a more tailored surgical approach for each patient. Interestingly, their study also reported that $40 \%$ of surgeons changed their surgical methods and plans after viewing the VR recreations of the kidneys. Though no significant benefits were seen in knowledge tests after VR interventions in the studies by Pulijala and colleagues, the VR programme nonetheless provided an excellent opportunity for students to learn and practice practical skills for use in surgery (Pulijala et al., 2018a, 2018b). Finally, a study by Maresky and colleagues demonstrated a significant increase of $26.4 \%$ on visual-spatial questions about the human heart between pre- and post-tests after intervention with a VR human heart compared to a control group using conventional learning materials and independent study (Maresky et al., 2019).

\section{Blending of learning materials and the effects on VR intervention study results}

When considering the mixed results of the VR intervention studies in this review, it is important to note that the majority of biomedical science education studies implemented novel VR tools alongside lectures, textbooks, anatomical atlases, CT images and dissections, with only two studies comparing a solely VR intervention against another educational tool. As such, the effect of the VR intervention could have been confounded in these studies. Further studies comparing solely VR interventions against conventional materials are needed to clarify the effect VR can have on a student's learning.

These studies do, however, demonstrate that novel VR programmes can be implemented into various curricula without detrimental results on the whole. In the SAMR model of technology implementation in education (Substitute, Augment, Modify and Redefine), new technologies can simply enhance the learning experience by replacing old technologies ( $\mathrm{S}$ and $\mathrm{A}$ ), or transform it with significant task redesigns or creation (M and R) (Hamilton, Rosenberg, \& Akcaoglu, 2016). As VR implementation practices and the programmes themselves improve and become more targeted, it is reasonable to assume that VR in combination with other teaching materials could provide a deeper learning experience for students.

\section{Tools and implementation must be fit for purpose}

Results produced by some studies demonstrate that one cannot simply create a VR programme and expect transformations in student learning outcomes; any VR tools developed must be fit for purpose and implemented into curricula appropriately. For example, the study by Makransky and colleagues (Makransky et al., 2019) utilised a desktop computer programme that had been converted into an HMD VR programme and also severely limited the interactivity students could have with the virtual environment through a lack of appropriate hand controls. Ultimately, this study exhibited negative results after the VR intervention. Conversely, Maresky and colleagues utilised a purpose-built model of the human heart in their VR intervention and saw significant benefits to student learning and understanding, particularly for visual-spatial understanding, as measured by the difference between pre- and post-intervention tests (Maresky et al., 2019). Additionally, Parkhomenko and colleagues used purpose-built VR tools in their study and saw increases in self-perceived confidence and understanding of 
upcoming surgeries in their subjects (Parkhomenko et al., 2018), though this is qualified by the fact that this intervention was less about learning new anatomy, as exploring variation in anatomy between patients. As the subjects in this study were experts, it would be interesting to know whether trainee surgeons learn anatomy better with the same VR tools. As such, educators and software designers ought to work together in order to create targeted learning tools in VR.

Emphasis should also be placed on the interactivity of any VR tools developed, as well as how they are implemented into curricula. Earlier studies have shown that visual-spatial knowledge improved when there was even limited interactivity possible with virtual anatomical models as opposed to none (Garg et al., 2001; Garg et al., 2002; Garg et al., 1999). Additionally, the negative results seen in Makransky and colleagues' study could also be attributed to the lack of intuitive, interactive hand controls with which to manipulate the environment. In relation to implementation into curricula, the time spent on learning tasks in VR could be important. The study by Maresky and colleagues allowed approximately 30 minutes of interaction and saw great benefits, whilst that by Stepan and colleagues (Stepan et al., 2017) allowed only 10 minutes in VR and showed minimal difference between study and control groups.

\section{In summary}

Bioscience and Medicine require a firm understanding of the variety of structures present in an organism, how they relate to one another in space and how they function dynamically over time. The sum of the studies presented here show that VR has mixed results in effectively improving student's learning and spatial understanding of bodily structures. However, the studies also show great promise for the technology should the appropriate tools be properly developed and delivered. Having VR for the sake of having VR won't fly; the VR learning resources need to be built with learning outcomes in mind and the appropriate scaffolds in place to support the learning experience. Unfortunately, though a number of studies have demonstrated positive benefits for the learning of various anatomical structures, such as the heart and brain, few studies have yet demonstrated specific improvement in the understanding of the dynamic processes of these structures, an area which will hopefully be further explored in future.

\section{Scalability}

The cost of HMD has undoubtedly fallen in recent years (Castelvecchi, 2016; Riva \& Wiederhold, 2015), with a high-end 'Oculus Rift S' HMD VR system currently priced at AU\$649 and a VR-ready computer costing approximately AU\$1500. No study known has shown the use of VR in a large cohort; the studies discussed in this review have all had less than 200 students, regardless of the technology and its application. This is important, as around the world, more and more students are entering university-level education. In Australia alone, the amount of students at university in 2017 has nearly doubled to over 1.5 million from 2001 figures (Australian Government Department of Education and Training, 2018). This lack of experience demonstrating that HMD VR can be deployed to a vast number of students remains a hurdle to the practicality of its implementation by educators and institutions following evidence-based practices. However, there is a case to be made that this hurdle can be overcome relatively painlessly, as many science courses currently employ multiple practical classes that 
Table 1: A summarised list of the papers discussed in Section 4, giving details to their field of study, their measurement methods and notable outcomes.

\begin{tabular}{|c|c|c|c|c|}
\hline $\begin{array}{l}\text { Paper } \\
\text { Authors }\end{array}$ & Field & $\begin{array}{l}\text { Time in VR } \\
\text { and type of } \\
\text { VR }\end{array}$ & Measurement & Notable Outcomes \\
\hline $\begin{array}{l}\begin{array}{l}\text { Immersive virtual } \\
\text { reality as a teaching } \\
\text { tool for neuroanatomy; }\end{array} \\
\text { Stepan, } \\
\text { Zeiger, } \\
\text { Hanchuk, } \\
\text { Del Signore, } \\
\text { Shrivastava, } \\
\text { Govindaraj and Iloreta, } \\
2017\end{array}$ & Neuroanatomy & $\begin{array}{l}10 \text { minutes } \\
\text { HMD VR }\end{array}$ & $\begin{array}{l}\text { Pre-/Post-quiz on } \\
\text { neuroanatomy knowledge; } \\
\text { retention quiz } 8 \text { weeks } \\
\text { later } \\
\text { Subjective learning } \\
\text { experience survey } \\
\text { Instructional Materials } \\
\text { Methods Survey (student } \\
\text { motivation) }\end{array}$ & $\begin{array}{l}\text { No significant difference in any knowledge quizzes, nor } \\
\text { between control and study groups } \\
\text { VR group found their tools significantly more engaging, } \\
\text { enjoyable and useful for learning } \\
\text { VR group scored significantly higher on the IMMS }\end{array}$ \\
\hline $\begin{array}{l}\text { Virtual reality and } \\
\text { cardiac anatomy: } \\
\text { Exploring immersive } \\
\text { three-dimensional } \\
\text { cardiac imaging, a pilot } \\
\text { study in undergraduate } \\
\text { medical anatomy } \\
\text { education; } \\
\text { Maresky, Oikonomou, } \\
\text { Ali, Ditkofsky, Pallak } \\
\text { and Ballyk, 2019 }\end{array}$ & $\begin{array}{l}\text { Cardiac } \\
\text { anatomy }\end{array}$ & $\begin{array}{l}30 \text { minutes } \\
\text { HMD VR }\end{array}$ & $\begin{array}{l}\text { Pre-/post-quiz on } \\
\text { cardiac anatomy (half } \\
\text { conventional questions, } \\
\text { half visual-spatial } \\
\text { questions) }\end{array}$ & $\begin{array}{l}\text { VR group had significantly higher results overall and in } \\
\text { each type of question }\end{array}$ \\
\hline $\begin{array}{l}\text { Adding immersive } \\
\text { virtual reality to a } \\
\text { science lab simulation }\end{array}$ & $\begin{array}{l}\text { Simulation of } \\
\text { a Science Lab } \\
\text { (Mammalian } \\
\end{array}$ & $\begin{array}{l}\text { 15-minutes } \\
\text { in HMD VR }\end{array}$ & $\begin{array}{l}\text { Knowledge test and } \\
\text { Transfer test (Both } \\
\text { completed } 3 \text { times }\end{array}$ & $\begin{array}{l}\text { When PC was either a } 1^{\text {st }} \text { - or } 2^{\text {nd }} \text {-intervention, students } \\
\text { gained more knowledge between tests }\end{array}$ \\
\hline
\end{tabular}




\begin{tabular}{|c|c|c|c|c|}
\hline $\begin{array}{l}\text { causes more presence } \\
\text { but less learning; } \\
\text { Makransky, Terkildsen } \\
\text { and Mayer, } 2019\end{array}$ & $\begin{array}{l}\text { Transient } \\
\text { Protein } \\
\text { Expression, } \\
\text { cell culturing, } \\
\text { cell } \\
\text { transfection, } \\
\text { protein } \\
\text { expression) }\end{array}$ & $\begin{array}{l}\text { 15-minutes } \\
\text { on flat- } \\
\text { screen } \\
\text { computer }\end{array}$ & $\begin{array}{l}\text { throughout procedure } \\
\text { without change) } \\
\text { Self reported survey on } \\
\text { presence, learning } \\
\text { experience and } \\
\text { satisfaction } \\
\text { Brain cognitive load } \\
\text { EEG results }\end{array}$ & $\begin{array}{l}\text { VR group had significantly higher presence ratings. No } \\
\text { significant difference in learning experience or } \\
\text { satisfaction } \\
\text { VR caused significantly more cognitive overloading } \\
\text { during second intervention only }\end{array}$ \\
\hline $\begin{array}{l}\text { Evaluation of } \\
\text { neuroanatomical } \\
\text { training using a 3D } \\
\text { visual reality model; } \\
\text { Brewer, Wilson, } \\
\text { Eagleson and de } \\
\text { Ribaupierre, } 2012\end{array}$ & Neuroanatomy & $\begin{array}{l}\text { Experiment } \\
\text { A: } 15 \\
\text { minutes } \\
\text { flat-screen } \\
\text { computer } \\
\text { Experiment } \\
\text { B: } 1.5 \text {-hour } \\
\text { "digital lab" }\end{array}$ & Post-test & $\begin{array}{l}\text { No significant difference in post-test scores between } \\
\text { groups, regardless of previous experience or experiment }\end{array}$ \\
\hline $\begin{array}{l}\text { Medical Student } \\
\text { Retention of Embryonic } \\
\text { Development: Impact } \\
\text { of the Dimensions } \\
\text { Added by Multimedia } \\
\text { Tutorials; } \\
\text { Marsh, Giffin and } \\
\text { Lowrie, } 2008\end{array}$ & $\begin{array}{l}\text { Embryonic } \\
\text { development }\end{array}$ & $\begin{array}{l}\text { Time not } \\
\text { specified (at } \\
\text { student's } \\
\text { leisure) } \\
\text { Flat-screen } \\
\text { computer } \\
\text { animation }\end{array}$ & $\begin{array}{l}\text { Short term: quiz directly } \\
\text { after intervention } \\
\text { Long term: quiz 4-16 } \\
\text { months after intervention }\end{array}$ & $\begin{array}{l}\text { VR group significantly higher on short-term retention if } \\
\text { previously exposed to topic (not if recently exposed) } \\
\text { Significantly higher results on long-term retention quiz } \\
\text { at } 4 \text { - and } 16 \text {-months after intervention if there was } \\
\text { repeated exposure to VR (after } 1^{\text {st }} \text { and } 2^{\text {nd }} \text { lectures with } \\
\sim 6 \text { months between classes). } \\
\text { No significant difference on long-term quiz if only } \\
\text { exposed to VR after second lecture. }\end{array}$ \\
\hline
\end{tabular}




\begin{tabular}{|c|c|c|c|c|}
\hline $\begin{array}{l}\text { Effectiveness of } \\
\text { immersive virtual } \\
\text { reality in surgical } \\
\text { training; } \\
\text { Pulijala, Ma, Pears, } \\
\text { Peebles and Ayoub, } 2018\end{array}$ & $\begin{array}{l}\text { Maxillofacial } \\
\text { surgery }\end{array}$ & $\begin{array}{l}45 \text { minutes } \\
\text { HMD VR }\end{array}$ & $\begin{array}{l}\text { Pre-/post-knowledge } \\
\text { tests } \\
\text { Self-reported confidence } \\
\text { survey (pre-/post- } \\
\text { intervention) }\end{array}$ & $\begin{array}{l}\text { VR group did not perform significantly better than } \\
\text { control group } \\
\text { VR group had significantly higher gains in confidence } \\
\text { than control }\end{array}$ \\
\hline $\begin{array}{l}\text { Educational effects of a } \\
\text { virtual reality } \\
\text { simulation system for } \\
\text { the constructing of self- } \\
\text { built PCs; } \\
\text { Teranishi and Yamagishi, } \\
2018\end{array}$ & $\begin{array}{l}\text { Computer } \\
\text { assembly }\end{array}$ & $\begin{array}{l}\text { Time not } \\
\text { specified } \\
\text { (tutorial } \\
\text { class, } \\
\text { assumed to } \\
\text { be } \sim 60 \\
\text { minutes) } \\
\text { HMD VR }\end{array}$ & $\begin{array}{l}\text { Same knowledge test } \\
\text { applied before and after } \\
\text { intervention (half of } \\
\text { questions concerning the } \\
\text { naming of parts, half } \\
\text { concerning the placement } \\
\text { of parts) }\end{array}$ & $\begin{array}{l}\text { Significant improvements on questions relating to the } \\
\text { placement of parts, but not for the naming of parts; } \\
\text { no control group }\end{array}$ \\
\hline
\end{tabular}


run for several hours at a time, or other, shorter tutorial classes as a part of their curriculum (Sheikh, Barry, Gutierrez, Cryan, \& O'Keeffe, 2016; Turney, 2007). HMD VR sessions, if done properly, could present to be no different to these already established course components. The Digital Learning Hub at the University of Melbourne, for instance, had 16 HMD VR systems available for use as of May, 2019. If one was to implement 30-minute VR sessions into a course and run sessions for 7 hours a day, 224 students could interact with the VR tool in a single day assuming maximal attendance. In a working week, 1,120 students could be processed through the VR sessions.

\section{Conclusion}

The educational potential of VR is a growing field of interest for many researchers and institutions. Thus far, VR has had mixed results in improving the learning experience for students and it is evident that learning tools need to be carefully and thoughtfully created and implemented in order to provide an authentic, engaging learning experience for students and thus drive their engagement, enjoyment and interest in a subject. Many studies have implemented VR tools alongside a variety of other conventional tools and experiences, perhaps influencing the results of these studies. There is further room in the literature for studies that directly compare conventional tools against VR tools as well as against VR tools plus conventional tools. Finally, evidence hurdles still exist for the technology in regard to its scalability in order to meet the ever growing populations of educational institutions, though these challenges are not insurmountable given technological advancements and reductions in cost.

\section{Acknowledgements}

No financial support was given in the creation of this literature review. The authors would like to thank the Digital Learning Hub (previously the Virtual Reality Learning Studio) at the University of Melbourne, Victoria, Australia for access to their virtual reality classrooms, equipment and applications. Please note; Dr Charles Sevigny is employed as the Director of the Digital Learning Hub, though this is an academic position. Further, the Digital Learning Hub is not a commercial enterprise, but an academic one.

\section{References}

Australian Government Department of Education and Training (2018). Higher Education Trends - Chart Pack. Retrieved March, 2019, from https://app.powerbi.com/view?r=eyJrIjoiOTcwODY3ZGItNTk3OS00ZWRjLTg2Y2UtNDR1YTMyY2MzNj ExIiwidCI6ImRkMGNmZDE1LTQ1NTgtNGIxMi04YmFkLWVhMjY5ODRmYzQxNyJ9.

Betihavas, V., Bridgman, H., Kornhaber, R., \& Cross, M. (2016). The evidence for 'flipping out': A systematic review of the flipped classroom in nursing education. Nurse Education Today, 38, 15-21.

Borrel, A., \& Fourches, D. (2017). RealityConvert: a tool for preparing 3D models of biochemical structures for augmented and virtual reality. Bioinformatics, 33(23), 3816-3818.

Botella, C., Serrano, B., Banos, R. M., \& Garcia-Palacios, A. (2015). Virtual reality exposure-based therapy for the treatment of post-traumatic stress disorder: a review of its efficacy, the adequacy of the treatment protocol, and its acceptability. Neuropsychiatric Disease and Treatment, 11, 2533-2545.

Brewer, D. N., Wilson, T. D., Eagleson, R., \& de Ribaupierre, S. (2012). Evaluation of neuroanatomical training using a 3D visual reality model. Studies in Health Technology and Informatics, 173, 85-91.

Castelvecchi, D. (2016). Low-cost headsets boost virtual reality's lab appeal [Electronic Version]. Nature, 533(7602), 153-154.

Cha, Y. W., Dou, M., Chabra, R., Menozzi, F., State, A., Wallen, E., \& Fuchs, H. (2016). Immersive Learning Experiences for Surgical Procedures. Studies in Health Technology and Informatics, 220, 55-62.

Chessa, M., Maiello, G., Borsari, A., \& Bex, P. J. (2016). The Perceptual Quality of the Oculus Rift for Immersive Virtual Reality. Human-Computer Interaction. 34(1), 51-82 
Chirico, A., Lucidi, F., De Laurentiis, M., Milanese, C., Napoli, A., \& Giordano, A. (2016). Virtual Reality in Health System: Beyond Entertainment. A Mini-Review on the Efficacy of VR During Cancer Treatment. Journal of Cellular Physiology, 231(2), 275-282.

Cho, B.H., Ku, J., Jang, D. P., Kim, S., Lee, Y. H., Kim, I. Y., Kim, S. I. (2002). The Effect of Virtual Reality Cognitive Training for Attention Enhancement. Cyber Psychology \& Behavior, 5(2), 129-137.

Codd, A. M., \& Choudhury, B. (2011). Virtual reality anatomy: Is it comparable with traditional methods in the teaching of human forearm musculoskeletal anatomy? Anatomical Sciences Education, 4(3), 119-125.

Collins, J. W., \& O'Brien, N. P. (2011). The Greenwood dictionary of education [electronic resource] (2nd ed. ed.). Greenwood Publishing Group.

Freeman, S., Eddy, S. L., McDonough, M., Smith, M. K., Okoroafor, N., Jordt, H., \& Wenderoth, M. P. (2014). Active learning increases student performance in science, engineering, and mathematics. Proceedings of the National Academy of Sciences of the United States of America, 111(23), 8410-8415.

Freina, L., \& Ott, M. (2015). A literature review on immersive virtual reality in education: state of the art and perspectives. Paper presented at the Conference eLearning and Software for Education. (1), 133-141

Garg, A. X., Norman, G., \& Sperotable, L. (2001). How medical students learn spatial anatomy. The Lancet, 357(9253), 363-364.

Garg, A. X., Norman, G. R., Eva, K. W., Spero, L., \& Sharan, S. (2002). Is There Any Real Virtue of Virtual Reality?: The Minor Role of Multiple Orientations in Learning Anatomy from Computers. Academic Medicine: Journal of the Association of American Medical Colleges. 77(10), 97-99

Garg, A. X., Norman, G. R., Spero, L., \& Maheshwari, P. (1999). Do virtual computer models hinder anatomy learning? Academic Medicine: Journal of the Association of American Medical Colleges. 74(10 supplemental), 87-89.

Goddard, T. D., Brilliant, A. A., Skillman, T. L., Vergenz, S., Tyrwhitt-Drake, J., Meng, E. C., \& Ferrin, T. E. (2018). Molecular Visualization on the Holodeck. Journal of Molecular Biology, 430(21), 3982-3996.

Hamilton, E. R., Rosenberg, J. M., \& Akcaoglu, M. (2016). The Substitution Augmentation Modification Redefinition (SAMR) Model: a Critical Review and Suggestions for its Use. TechTrends: For Leaders in Education \& Training, 60(5), 433-441.

Harrington, C. M., Kavanagh, D. O., Quinlan, J. F., Ryan, D., Dicker, P., O'Keeffe, D., . . Tierney, S. (2018). Development and evaluation of a trauma decision-making simulator in Oculus virtual reality. The American Journal of Surgery, 215(1), 42-47.

Hoffman, H. G., Patterson, D. R., Seibel, E., Soltani, M., Jewett-Leahy, L., \& Sharar, S. R. (2008). Virtual reality pain control during burn wound debridement in the hydrotank. The Clinical Journal Of Pain, 24(4), 299-304.

Jang, H. (2008). Supporting students' motivation, engagement, and learning during an uninteresting activity. Journal of Educational Psychology, 100(4), 798-811.

Kahu, E., Nelson, K., \& Picton, C. (2017). Student interest as a key driver of engagement for first year students. Student Success, 8(2), 55-66.

Koh, G. C.-H., Khoo, H. E., Wong, M. L., \& Koh, D. (2008). The effects of problem-based learning during medical school on physician competency: a systematic review, 178(1), 34-41.

Mahaffey, A. L. (2018). Interfacing virtual and face-to-face teaching methods in an undergraduate human physiology course for health professions students. Advances in Physiology Education, 42(3), 477-481.

Makransky, G., Terkildsen, T. S., \& Mayer, R. E. (2019). Adding immersive virtual reality to a science lab simulation causes more presence but less learning. Learning \& Instruction, 60, 225-236.

Maresky, H. S., Oikonomou, A., Ali, I., Ditkofsky, N., Pakkal, M., \& Ballyk, B. (2019). Virtual reality and cardiac anatomy: Exploring immersive three-dimensional cardiac imaging, a pilot study in undergraduate medical anatomy education. Clinical Anatomy, 32(2), 238-243.

Marsh, K. R., Giffin, B. F., \& Lowrie, D. J., Jr. (2008). Medical Student Retention of Embryonic Development: Impact of the Dimensions Added by Multimedia Tutorials. Anatomical Sciences Education, 1(6), 252-257

Merchant, Z., Goetz, E. T., Cifuentes, L., Keeney-Kennicutt, W., \& Davis, T. J. (2014). Effectiveness of virtual reality-based instruction on students' learning outcomes in K-12 and higher education: A meta-analysis. Computers \& Education, 70, 29-40.

Mestre, D. R. (2006). Immersion and Presence. Le traité de la réalité virtuelle, Paris: Ecole des Mines de Paris, 309-338

Michael, J. (2006). Where's the Evidence that Active Learning Works? Advances in Physiology Education, 30(4), 159-167.

O'Connor, M., Deeks, H. M., Dawn, E., Metatla, O., Roudaut, A., Sutton, M., . . Glowacki, D. R. (2018). Sampling molecular conformations and dynamics in a multiuser virtual reality framework. Science Advances, 4(6), 2731-2740 
Parkhomenko, E., O'Leary, M., Safiullah, S., Walia, S., Owyong, M., Lin, C., . . Clayman, R. (2018). Pilot Assessment of Immersive Virtual Reality Renal Models as an Educational and Preoperative Planning Tool for Percutaneous Nephrolithotomy. Journal of Endourology, 33(4), 283-288.

Pulijala, Y., Ma, M., Pears, M., Peebles, D., \& Ayoub, A. (2018a). Effectiveness of Immersive Virtual Reality in Surgical Training-A Randomized Control Trial. International Journal of Oral and Maxillofacial Surgery, 76(5), 1065-1072.

Pulijala, Y., Ma, M., Pears, M., Peebles, D., \& Ayoub, A. (2018b). An innovative virtual reality training tool for orthognathic surgery. International Journal of Oral \& Maxillofacial Surgery, 47(9), 1199-1205.

Riva, G., \& Wiederhold, B. K. (2015). The New Dawn of Virtual Reality in Health Care: Medical Simulation and Experiential Interface. Studies in Health Technology and Informatics, 219, 3-8.

Sheikh, A. H., Barry, D. S., Gutierrez, H., Cryan, J. F., \& O'Keeffe, G. W. (2016). Cadaveric Anatomy in the Future of Medical Education: What Is the Surgeons View? Anatomical Sciences Education, 9(2), 203-208.

Sisk, R. J. (2011). Team-Based Learning: Systematic Research Review. Journal of Nursing Education, 50(12) 665-675.

Stepan, K., Zeiger, J., Hanchuk, S., Del Signore, A., Shrivastava, R., Govindaraj, S., \& Iloreta, A. (2017). Immersive virtual reality as a teaching tool for neuroanatomy. International Forum Of Allergy \& Rhinology, 7(10), 1006-1013. doi:10.1002/alr.21986

Teranishi, S., \& Yamagishi, Y. (2018). Educational Effects of a Virtual Reality Simulation System for Constructing Self-Built PCs. Journal of Educational Multimedia and Hypermedia, 27(3), 411-423.

Turney, B. W. (2007). Anatomy in a Modern Medical Curriculum. Annals of The Royal College of Surgeons of England, 89(2), 104-107. 